\title{
REPRESENTACIÓN DE LA ACCIÓN POLÍTICA DE LOS ESTUDIANTES CHILENOS. MOVILIZACIÓN DE SIGNIFICADOS EN REDES SOCIALES
}

\author{
CAMILA CÁRdENAS NEIRA*
}

\begin{abstract}
RESUMEN
Este artículo explora la representación de la acción política estudiantil mediante las redes sociales, a fin de establecer tres lugares de enunciación que funcionan como espacios de resistencia simultáneos: las calles, las aulas y las pantallas. Desde el análisis crítico del discurso se examinan publicaciones seleccionadas de Facebook y Twitter entre agosto de 2011 y julio de 2013. Una perspectiva comunicativa basada en el eje resemiotización/resemantización permite observar el vínculo entre topologías y gnoseologías emergentes, reformulando las prácticas de hetero y autorrepresentación online en cuanto procesos de identificación complejos y en permanente tensión. Estos se recontextualizan a partir del establecimiento de una base sociocognitiva común: los significados que los estudiantes movilizan de unos espacios de discursividad a otros reconstruyen representaciones sustentadas en una intertextualidad marcada histórica y generacionalmente, con especial énfasis en los saberes y memorias compartidas.
\end{abstract}

\footnotetext{
PALABRAS CLAVE: MOVIMIENTO ESTUDIANTIL CHILENO, DISCURSO ONLINE, REPRESENTACIÓN POLÍTICA
}

* Doctoranda en Traducción y Ciencias del Lenguaje. Miembro del Grupo de Estudios del Discurso (GED) de la Universitat Pompeu Fabra, Barcelona, España. E-Mail: camila.cardenas.neira@gmail.com. 


\title{
REPRESENTAÇÃO DA AÇÃO POLÍTICA DOS ESTUDANTES CHILENOS: MOBILIZAÇÃO DE SIGNIFICADOS NAS REDES SOCIAIS
}

\begin{abstract}
RESUMO
Este artigo visa explorar a representação da ação política dos estudantes nas redes sociais, com o objetivo de estabelecer três lugares de enunciação que funcionam como espaços de resistência simultâneos: as ruas, as aulas e as telas. Com base na análise crítica do discurso se examinam publicações selecionadas do Facebook e Twitter entre agosto de 2011 e julho de 2013. Uma perspectiva comunicativa baseada no eixo ressemiotização/ressemantização permite observar o vínculo entre as topologias e gnosiologias emergentes, reformulando as práticas hétero e auto- representação online como os processos de identificação complexos e em permanente tensão. Estes se recontextualizam a partir do estabelecimento de uma base sóciocognitiva comum: os significados que os estudantes mobilizam de certos espaços de discursividade a outros reconstruindo representações sustentadas em uma intertextualidade marcada histórica e de maneira geracional, com especial ênfase nos saberes e memórias compartilhadas.

\section{PALAVRAS CHAVE: MOVIMENTO ESTUDANTIL CHILENO, DISCURSO ONLINE, REPRESENTAÇÃO POLÍTICA}

\section{REPRESENTATION OF POLITICAL ACTION AMONG CHILEAN STUDENTS: DISSEMINATION OF MEANINGS IN SOCIAL MEDIA}

\begin{abstract}
This paper examines the performance of the political action that Chilean students generated in social media. The purpose of the study is established three places of enunciation that work as simultaneous spaces of resistance: streets, classrooms, and screens. Selected Facebook and Twitter publications that range from August 2011 to July 2013 will be studied through the lens of Critical Discourse Analysis. A communicative perspective based on the focus analysis of resemiotization/resemantization permits to observe the link between topologies and emerging gnoseologies, reformulating online hetero and auto-representation practices in terms of complex identification processes in permanent tension. These are recontextualized from the establishment of a common sociocognitive basis: the meanings that students move from some discursive spaces to others reconstruct representations, based on an intertextuality marked historically and generationally with special emphasis on knowledge and shared memories.
\end{abstract}

KEY WORDS: CHILEAN STUDENT MOVEMENT, ONLINE DISCOURSE, POLITICAL REPRESENTATION 


\section{INTRODUCCIÓN: DE JÓVENES, MOVIMIENTOS Y SIGNIFICADOS}

INDAGAR CÓMO SE REPRESENTA la acción política juvenil en la historia reciente chilena constituye una exploración nueva desde los «estudios del discurso». La investigación sobre juventud ha tenido desarrollos desde enfoques sociológicos, antropológicos y psicológicos, pero poco se ha dicho desde el análisis de los discursos que presentan a estos actores y explican su incidencia social en las últimas décadas. Esta preocupación responde a un contexto más amplio que ha convocado a las nuevas generaciones de una forma inédita en la postdictadura, desestabilizando la tendencia invisibilizadora que ha estereotipado su participación en el pasado reciente (Cárdenas, 2012, 2011a, 2011b). Pese a la reproducción de representaciones que desdibujan su actuación política, es un hecho que la acción juvenil se encuentra conectada a la historia de los movimientos sociales desde principios del siglo XX (Garcés, 2012), con especial énfasis en el carácter estudiantil de la protesta (Aguilera, 2012).

Pareciera existir, por tanto, una disyunción entre la historia que se cuenta (story) y la historia que ocurrió (history) (Ricoeur, 2010; Trouillot, 1995), de modo tal que la visibilización de la juventud se ha jugado principalmente en su inteligibilidad discursiva; la pugna por la representación entraña conflictos de poder-decir (Martín Rojo y Whittaker, 1998) que determinan aquello que se vuelve comunicable, al margen de lo efectivamente acontecido. Cuando se construyen discursos para explicar a la opinión pública la acción juvenil, un adultocentrismo históricamente reproducido (Duarte, 2012) controla formas de representación que resaltan la incapacidad de los jóvenes de generar propuestas políticas realistas, invisibilizándolos como sujetos sociales. Esta visión recoge una tendencia deshistorizadora más amplia sobre la juventud, desde la que se descalifican las nuevas formas de agrupamiento por tener un supuesto carácter idealista y pasajero.

$\mathrm{Si}$ es efectivo, entonces, que los discursos dominantes han negado, marginado y ocultado la presencia de los actores juveniles en el pasado reciente (Cárdenas, en prensa):

¿Cómo se explican los movimientos juveniles que han emergido en la postdictadura chilena desafiando estas representaciones dominantes?, ¿cuál es la interfaz sociocognitiva que separa las representaciones discursivas comunicadas, de las representaciones que los jóvenes se apropian para irrumpir en la escena social?, ¿qué factores psicosociales, 
políticos o históricos son adecuados para explicar la disyunción que confronta estos discursos hegemónicos a los contradiscursos que reclaman el reconocimiento de las experiencias juveniles?

Ante las coerciones del poder-decir, los jóvenes responden mediante el poder-hacer, articulando movilizaciones que les han permitido (re)significar una coyuntura sociopolítica crítica: demandas por una educación pública, gratuita y de calidad han signado el campo educativo como un campo de lucha política. El movimiento estudiantil ha articulado así una impugnación mayor al sistema representativo y democrático chileno (Cárdenas, 2013), poniendo en tela de juicio un modelo que profundiza la desigualdad y la segregación social. En este escenario, una perspectiva que atienda únicamente los efectos derivados de las representaciones dominantes resulta insuficiente. Desde el momento en que las movilizaciones estudiantiles construyen nuevos lugares de enunciación, los jóvenes reivindican su condición de interlocutores legítimos.

En este escenario, el papel de los discursos hegemónicos entra en cuestionamiento cuando los flujos informativos se expanden hacia las esferas virtuales, pues estas, soportadas en los servicios de la web 2.0, conforman lugares de interacción dialógica que posibilitan su resemantización. Los estudiantes demuestran reconocer la función manipuladora de las élites político-mediáticas, y se proponen confrontarla mediante la gestión estratégica de contenidos en entornos online, con el propósito de delinear sus formas de participación política y definir su impacto social ante la ciudadanía.

De este modo, el estudio de los discursos online que modelan significados polémicos sobre la acción política juvenil se presenta como un aporte necesario, en tanto se plantea la articulación de factores lingüísticos, sociocognitivos e histórico-políticos para la comprensión de la movilización estudiantil en el contexto de postdictadura. Con ello, resulta posible atender procesos de reproducción ideológica vinculados con la conformación de identidades juveniles y otras formas de cognición social relevantes como actitudes grupales, conocimientos compartidos y memorias intrageneracionales.

Este artículo propone una reflexión sobre las prácticas discursivas que representan la acción política del movimiento estudiantil (2011-2013) derivadas del tratamiento informativo efectuado en redes sociales. Mediante el análisis semiodiscursivo de un conjunto de textos - escritos, visuales y audiovisuales - seleccionados de perfiles de Facebook y 
Twitter, ${ }^{1}$ se reconocen tres espacios de actuación juvenil que funcionan como lugares de resistencia, tensión y negociación de significados políticos: las calles, las aulas y las pantallas. El énfasis de esta indagación se sitúa en el carácter comunicativo del eje resemiotización/resemantización que organiza dichos espacios de discursividad, los que visibilizan conjuntamente una pugna transversal por la hetero y la autorepresentación juvenil.

En primer lugar, se delinean dos enfoques teóricos que esclarecen: a) la gestión estratégica que los jóvenes realizan de entornos online con fines políticos, y; b) las condiciones históricas que subyacen a los usos ciberpolíticos de los estudiantes movilizados. En segundo lugar, se ofrece una caracterización de los espacios de resistencia delimitados, así como explicaciones de las funciones semiodiscursivas de los textos considerados. En tercer lugar, se propone una síntesis que conecte las aportaciones teóricas discutidas con las reflexiones derivadas del análisis de redes sociales.

\section{ESTUDIANTES INFORMADOS:}

\section{¡AHORA NOSOTROS DAMOS LAS NOTICIAS!}

El movimiento estudiantil chileno se ha mantenido vigente los últimos años (2011-2013) apoyado del uso estratégico de las redes sociales que han operado como importantes canales para la difusión de contradiscursos, con ellas han respondido a las representaciones mediáticas dominantes. Lo que destaca de la actividad online de los estudiantes son los usos contrainformativos que han efectuado, tanto en lo que respecta a la gestión de flujos noticiosos provenientes de la prensa tradicional como en la creación de medios y contenidos propios. Estos usos no solo les han permitido visibilizarse e interactuar discursiva-

1 Se analizaron las páginas Estudiantes Informados [Movimientos Sociales] y Estudiantes Informados [Oficial], mediante el seguimiento de las publicaciones realizadas entre agosto de 2011 y julio de 2013. El análisis semiodiscursivo se complementó con la realización de una entrevista a sus administradores. Durante los primeros meses de funcionamiento las páginas generaron publicaciones diferenciadas: la primera produjo contenidos relacionados con la difusión de actividades de protesta, mientras que la segunda se valió de la reposición de noticias que trataron hitos vinculados al movimiento estudiantil. Con el paso del tiempo las cuentas terminaron fusionándose, prevaleciendo la segunda tendencia informativa. 
mente en el espacio público, sino que además los han legitimado como interlocutores efectivos.

\section{a) Juventud y política}

Diversos estudios internacionales coinciden en señalar que el siglo XXI se caracteriza por una crisis de representatividad que aleja a los jóvenes de los asuntos públicos. En esta línea, se introduce el planteamiento sobre la apatía juvenil para explicar el rechazo a experimentar un sentido de deber cívico (Ward y Vreese, 2011). Estos diagnósticos se basan en «la disminución de la participación electoral, el interés político, la membresía en partidos y la erosión del capital social» (Theocharis, 2012:165), lo que lleva a sostener que los jóvenes están muy desencantados de la política institucionalizada. Son las formas clásicas de participación, y particularmente aquellas convocadas por la autoridad gubernamental, las que resultan menos legítimas para la juventud (Fernández, 2012).

Lo que los jóvenes demuestran es incredulidad en la capacidad del estado de proteger y respetar sus derechos, ya que «se han visto a sí mismos como blancos de campañas de educación cívica o regímenes de responsabilización que los han construido como ciudadanos inadecuados» (Harris, Wyn y Younes, 2010:12). De esta manera, lo que distancia a la juventud de la política tradicional es la percepción de que sus voces y problemas no son escuchados. Así, mientras que autoridades e intelectuales se han focalizado en el diagnóstico de la apatía, los procesos y debates políticos siguen marginando a la juventud y estructurándose en torno a los intereses de los adultos (Harris, Wyn y Younes, 2010). De allí que cambiar el foco desde las deficiencias de la juventud a las limitaciones que precipita la privación de sus derechos, revela una relación mucho más compleja entre jóvenes y política formal que una mera indiferencia.

Bennett (2003) retoma la noción de hacedores cotidianos para caracterizar a estas nuevas generaciones. Ellas definen su propio sentido de lo político en relación con sus experiencias diarias y redes interpersonales. Esta inclinación se explica porque las discusiones informales entre pares serían formas «más interesantes y efectivas que los procesos políticos adultocéntricos» (Harris, Wyn y Younes, 2010:24). El punto crítico de esta aproximación es que tiende a suponerse que la capacidad política de los jóvenes disminuye cuando estos reemplazan repertorios convencionales de acción, como aquellos centrados en el 
gobierno y las afiliaciones partidistas, por prácticas más vinculadas con sus preocupaciones y rutinas diarias.

Algunos investigadores latinoamericanos sugieren que es posible «individualizar a los jóvenes que transitan al siglo XXI como la 'generación@'» (Portillo et al., 2012:140). Este término expresa tres tendencias de cambio: el acceso universal - aunque no necesariamente general- a las nuevas tecnologías, la erosión de las fronteras tradicionales entre los sexos y los géneros y el proceso de globalización cultural. Estos cruces permiten erigir una política cotidiana que restituye la ciudadanía juvenil mediante «formas de compromiso emocionales, expresivas y estéticas» (Harris, Wyn y Younes, 2010:14). De este modo, la participación activa en la toma de decisiones es significativa, ya que al poder dirigirlas son divertidas, informales y evitan la espesura de procesos políticos complejos (Vromen y Collin, 2010). Al respecto, Portillo et al. (2012) sintetizan que:

Mientras la política de los adultos espacializa en un solo lugar su práctica (el parlamento, los partidos políticos), la política cultural de los jóvenes la escenifica en la cotidianeidad (sus cuerpos, su sociabilidad, sus territorios más próximos). Y por otra parte, mientras la temporalidad política del mundo adulto se refiere a un largo plazo (un mañana mejor), la política cultural juvenil la instala en el corto plazo (un presente mejor). Esta otra configuración cultural es la base de muchos de los desencuentros de los actores juveniles y adultos cuando negocian la resolución de los conflictos. ¿Por qué esperar tanto tiempo cuando las reformas se pueden hacer hoy? Este parece ser el argumento generacional juvenil ante el mundo institucional (2012:158).

\section{b) Acción política y nuevas tecnologías}

La resignificación política encuentra en los espacios proporcionados por las tecnologías un frente de combate de doble significación: «como espacio de constitución de la acción colectiva juvenil que posibilita la toma de acuerdos entre diversos actores y como espacio para la respectiva difusión de actividades» (Portillo et al., 2012:158). En este punto resulta clave el uso de la web 2.0, en la medida en que ha constituido nuevos lugares de conflictividad y apropiación de recursos comunicativos que orientan la gestión informativa y la circulación de conocimientos.

Feixa, Pereira y Juris proponen denominar a estos jóvenes movilizados como «los 'novísimos movimientos sociales' (en plural)» 
(2009:423). Para estos autores, «una diferencia importante con los movimientos anteriores es que, por primera vez, los jóvenes no están, por definición, en una posición subalterna, en particular respecto de los cambios tecnológicos» (2009:428). Internet permite el despliegue de estrategias alternativas de activismo (Harris, Wyn y Younes, 2010), de manera tal que los jóvenes ven en la hibridación de lo lúdico con lo político la posibilidad de que las tecnologías estén al servicio de la protesta social (Rovira Sancho, 2013).

A fin de articular su participación política, los jóvenes utilizan internet para «promover sus objetivos, organizar y movilizarse con otros, establecer vínculos digitales entre sus ocupaciones y coordinar su línea de acción política offline» (Theocharis, 2012:165). En particular, los movimientos estudiantiles han sido capaces de desarrollar un carácter informativo bastante sofisticado, combinando el uso de viejas y nuevas plataformas que estructuran sus repertorios y marcos de acción.

Las redes sociales entregan un valor añadido a las prácticas juveniles, siendo una de las características más relevantes la posibilidad de tomar distancia de los medios de comunicación tradicionales. Según Bennett (2003), los jóvenes reconocen que los medios son en buena parte responsables de la negatividad con que la sociedad los percibe. De este modo, los movimientos juveniles intentan comunicarse directamente con la ciudadanía, tanto para transparentar sus propósitos de movilización, como para expresar los significados que fundamentan su protesta. De allí el carácter estratégico de las redes sociales como espacios de interacción y resistencia.

\section{c) Ciberpolítica y producción de canales contrainformativos}

Frente a la estereotipización que hacen los consorcios mediáticos de sus causas, los movimientos juveniles desplegados en las redes sociales tienen el resguardo de que el poder no puede intervenir en el flujo de la información que gestionan. La ciberpolítica afecta las formas de representación dominantes, las que son transformadas por la pluralización del espacio público cuando los sujetos marginalizados se organizan en lugares alternativos, ganando visibilidad (Millaleo, 2011). Una de las principales formas de pluralización es el carácter dialógico que supone la comunicación digital, pues ofrece la oportunidad de crear, administrar y propagar ideas disidentes, empleando las plataformas 
electrónicas como «contraesferas públicas de información y deliberación» (Millaleo, 2011:102).

Desde este punto de vista, las redes sociales pueden ser comprendidas como circuitos políticos (Tilly y Wood, 2010) que no solo organizan puntos de contacto, sino que constituyen el conjunto de fronteras, transacciones políticas y relaciones significativas entre los miembros. En forma similar, Tarrow (2011) habla de comunidades de protesta conformadas por grupos que comparten la voluntad de involucrarse en una participación sostenida. Para el caso chileno, Valenzuela, Arriagada y Scherman (2012) explicitan una relación positiva entre el uso de Facebook y la conducta de protesta: «los usuarios frecuentes están más propensos a protestar porque se dedican a actividades que son esenciales para la acción colectiva, como el aprendizaje, el intercambio y la formación de opiniones sobre cuestiones sociales, así como la construcción de una identidad común» (2012:5).

A esta irrupción tecnológica subyacen las constricciones mediáticas heredadas de la dictadura militar (Millaleo, 2011). Dichas limitaciones son reconocidas por los movimientos estudiantiles, quienes asumen el desafío de emplear las redes sociales para su propia gestión informativa. De esta manera, los estudiantes combinan fuentes periodísticas tradicionales con aquellas proporcionadas por medios alternativos y propios, propiciando una lógica de intermedialidad (Herkman, 2012) que modifica y resiste las formas unidireccionales de comunicación.

Esta capacidad de seleccionar contenidos y apropiárselos, renovando sus sentidos originales, conforma una nueva experiencia comunicativa que pone a la Internet al servicio de nuevas formas de interacción política (Östman, 2012). Para este autor, los contenidos generados por el usuario constituyen una experiencia distintiva «basada en la expresividad, la performatividad y la colaboración, en lugar de la recepción y el procesamiento pasivo» (2012:1005). Los consumidores de información puedan actuar también como productores - prosumidores-, de manera tal que estos nuevos modos de participación jueguen un papel destacado en la adquisición de actitudes, conocimientos y comportamientos políticos.

Ahora bien, más allá de las ventajas que proveen las redes sociales a los movimientos juveniles, es evidente que todavía hay tradiciones y hábitos poderosamente persistentes en la comunicación política (Herkman, 2012). Es necesario preguntarse, siguiendo a Tilly y Wood (2010), si acaso estos movimientos están cambiando realmente gracias 
a las nuevas tecnologías y, de ser así, en qué sentidos lo hacen. Para conseguir una visión equilibrada, debe evitarse el determinismo tecnológico y reconocer que muchos de los nuevos rasgos que presentan los movimientos sociales son el resultado de los cambios acaecidos en sus respectivos contextos sociopolíticos.

\section{3. 'LOS JÓVENES TAMBIÉN TENEMOS MEMORIA'}

Explorar las prácticas discursivas online que representan la acción política juvenil requiere profundizar no solo en el carácter comunicativo de la protesta estudiantil, sino que, especialmente, en el horizonte histórico que otorga una especificidad simbólica a sus interacciones públicas. Desde esta perspectiva, los estudiantes se movilizan a partir de un diagnóstico que evalúa la sociedad presente y propone cambios para transitar hacia el proyecto ciudadano deseado. Ellos no solo miran al futuro, sino que vuelven sistemáticamente al pasado para delinear los márgenes de esta transformación. En este sentido, politicidad e historicidad se funden, y de la lectura de esta relación se desprenden los marcos interpretativos que los discursos juveniles reivindican.

\section{a) Juventud chilena, rebeldía e inconformismo}

No puede comprenderse la categoría juventud en tanto constructo sociocultural sin considerar una perspectiva histórica (Muñoz, 2004; Goicovic, 2000). Atendiendo el pasado reciente, el periodo en que se sientan las bases de la investigación en juventud es concordante con los años más intensos de represión militar (Agurto, Canales y De La Maza, 1985). Aunque no son explícitamente definidos como jóvenes por la historia oficial (Cárdenas, 2012, 2011a), fueron los principales vulnerados por el genocidio perpetrado por la dictadura (Salazar y Pinto, 1999).

Con la transición pactada a la democracia, se establecen dos lineamientos centrales para comprender a los actores juveniles (Aguilera, 2009): a) el del sujeto parcial: incompleto en sus posibilidades de

2 Los textos destacados en negrita y comillas simples corresponden a rayados de murallas o pancartas empleadas en marchas que, resemiotizados, circularon por redes sociales en forma de fotografías, «posteos» reiterativos de diversa autoría, o videos de actuaciones públicas como congregaciones o «funas». 
acción sociocultural y política, y; b) el del sujeto anómico: incapacitado de integrarse socialmente por sí mismo. Una de las características que aglutina dichos ejes es la pérdida de agencia; no obstante, en ninguno de ellos se enlaza dicha pérdida a las consecuencias derivadas del pasado traumático y el impacto en sus memorias y actuación.

El estado chileno ejecutó durante los 90 un proyecto asistencialista que intentó proveer a los jóvenes de seguridades sociales en ámbitos como la educación y el trabajo, acotando su acción al ámbito individual y familiar. Paralelamente, las políticas escolares promovieron un discurso pedagógico que buscaba reducir el enfrentamiento, estabilizando y legitimando posiciones en torno a sucesos polémicos (Oteíza, 2006), como la vulneración de los derechos humanos por la dictadura, en concordancia con las pretensiones del oficialismo y la oposición de lograr acuerdos para superar el pasado. Se pretendió con ello que las nuevas generaciones integraran sus conocimientos de la historia reciente de la manera menos conflictiva posible.

Esto, sumado a la invisibilización sistemática de las luchas juveniles, configuró un escenario donde los movimientos estudiantiles parecieron emerger sin justificación. En efecto, hasta iniciada la década de los 2000, el discurso sobre la apatía política había conseguido suficientes adeptos, tanto en las esferas gubernamentales como intelectuales. Resultaban acordes al proyecto transicional las imágenes de una juventud homogénea, unida y apolítica, en tanto proyección de una sociedad homogénea, unida y apolítica (Muñoz, 2004).

Detrás de estos intentos por reforzar la naturalización de lo social (Lechner, 2006) pervive una actitud altamente adultocentrista que resalta la inmadurez y la incapacidad de los jóvenes de generar propuestas pragmáticas y eficientes (Valenzuela, 2007), argumento que, sostenidamente expuesto a la opinión pública, termina negándolos como sujetos totales (Chaves, 2005). Al establecerse estas narrativas de la negación (Aguilera, 2012), «los cuestionamientos surgidos desde las y los jóvenes hacia las bases legales y morales son vistos como actos delictivos, o en términos de política social, como 'excluidos'» (Chávez y Poblete, 2006:145).

No obstante, las movilizaciones recientes han obligado la revisión de los contenidos simbólicos asociados al vínculo política-juventud. Una creciente presencia pública de los movimientos juveniles expresa un profundo descontento con los marcos institucionales de la política, al tiempo que se considera a los jóvenes como legítimamente políticos desde lo social (Muñoz, 2011). Se han acentuado así dos formas distin- 
tas de comprender la política: una entendida como campo estructurado formalmente a nivel institucional y de gobierno, donde se establecen las relaciones de poder conectadas con la conducción general de la sociedad; y otra que se inclina por lo político, dimensión vinculada al modo cotidiano en que los sujetos juveniles asumen la construcción de la realidad social deseada, mediante instancias de sociabilidad, organizaciones civiles y movimientos ciudadanos (Muñoz, 2011).

\section{b) De actores secundarios a actores protagonistas}

Los estudiantes chilenos se han constituido en los últimos años como el actor social de mayor visibilización y articulación pública (Portillo et al., 2012). Desde los procesos de reforma (1967) y contrarreforma universitaria (1981), las jornadas de protesta contra Pinochet (19831987) y el plebiscito (1988), llegando al «mochilazo» (2001), la «revolución pingüina» (2006) y el periodo de movilizaciones iniciado en 2011, los jóvenes han jugado un papel crítico en el pasado reciente.

Estos han erigido la educación como un campo de lucha política, revelando las relaciones de desigualdad y segregación que fomenta el sistema educativo neoliberal (Cabalin, 2012). Junto con ello, han extendido sus efectos a una sociedad crecientemente precarizada, atravesada por las prácticas lucrativas que impone una nueva «dictadura de mercado», resguardada y reforzada por las dos coaliciones políticas que han gobernado el país.

En virtud de estos alcances, una perspectiva diacrónica resulta fundamental para comprender la movilización estudiantil con mayor anchura y profundidad. En primer lugar, conviene apuntar que lo que se ha venido gestando desde el 2001 no son movimientos distintos, sino el mismo visto como un continuum con múltiples focos de visibilización. En segundo lugar, aunque se ha intentado comparar el caso chileno con otras experiencias internacionales como los indignados españoles, los occupy de Estados Unidos o las primaveras árabes (Jackson, 2012), la movilización estudiantil ha perdurado, justamente, gracias a su tradición histórica organizativa: las federaciones constituyen el reservorio de la memoria del movimiento, lo que facilita su reproducción en el tiempo (Guzmán Concha, 2012).

El movimiento estudiantil ha llevado adelante un proceso de reencantamiento con lo público que, aun cuando no ha tenido una trayectoria homogénea, ha impactado en múltiples niveles las prácticas asociativas de la sociedad chilena (Aguilera, 2012). En efecto, los 
estudiantes han tenido la habilidad de traspasar la consigna «no al lucro» desde el ámbito específico de la educación a la sociedad en su totalidad.

En este sentido, el movimiento estudiantil ha colaborado en «la refundación ética de la política» (Portillo et al., 2012:159), lo que implica que la interacción juvenil conforma registros de politicidad que se activan cuando imperativos éticos así lo proponen: educación pública y gratuita, nacionalización de los recursos naturales, reforma tributaria o asamblea constituyente, constituyen demandas que se han expandido transversalmente en la sociedad chilena.

Los estudiantes han desplegado su acción en la esfera pública mediante la ocupación material y simbólica de espacios simultáneos como las calles, las aulas y las pantallas. Con ello han logrado difundir estratégicamente sus propias representaciones de mundo, en oposición a aquellas impuestas por las elites adultas y poderosas guardianas del modelo capitalista que el movimiento confronta.

\section{c) 'Somos la generación sin miedo'}

Una última característica del movimiento estudiantil chileno que merece ser subrayada es el carácter generacional de su actuación política. De acuerdo con Portillo et al., «una generación está marcada por los hechos históricos, políticos, mediáticos, culturales y tecnológicos que perfilan la memoria, los gustos, las prácticas de los que son jóvenes en ese periodo y que les permiten construir una identidad generacional a partir del reconocimiento e identificación de esas vivencias compartidas» (2012:169). La hermandad frente a los estímulos de una época (Margulis y Urresti, 1996) se expresa tanto en relación con los pares generacionales como con las generaciones precedentes. La comunicación intergeneracional funciona expresando las sucesivas síntesis con que se evalúan las experiencias colectivas y se construye un particular proyecto de sociedad.

A este respecto, los jóvenes han insistido en una identificación iluminadora: no somos hijos de su democracia, somos padres de su revolución. Con ello, esta generación busca tomar distancia de aquellas que experimentaron su juventud durante la dictadura militar, enfatizando no solo el cambio histórico, sino su rechazo al sistema político-económico heredado del régimen, cuya expresión tangible es la Constitución de 1980 que aún rige el país. Los jóvenes han asumido así la tarea de transformación social como un cambio deseable para las 
nuevas generaciones, las que merecen una experiencia democrática sustentada en una nueva institucionalidad.

Estas diferencias advierten que tanto los límites de las formas de movilización como la definición de lo que se convierte en protestable se sostiene en las situaciones que los actores pueden historizar: «allí se encuentran las trayectorias de protestas anteriores, los recursos acumulados [...] y la represión de la memoria» (Chaves y Núñez, 2012:369). Los estudiantes, junto con redefinir reflexivamente una experiencia histórica que, sin haber vivenciado, les ofrece múltiples horizontes de actuación (Jelin y Sempol, 2006), aplican este aprendizaje a las recientes experiencias de movilización, a fin de orientar la acción colectiva en curso y «no cometer los mismos errores del pasado».

Esto constata una «ruptura generacional entre las culturas políticas tradicionales y las políticas de las culturas juveniles» (Aguilera, 2010:94); los estudiantes persiguen no solo 'bajar la política del Olimpo' a las calles y las pantallas de ordenador, sino también resignificar el sentido de lo político mediante repertorios contestatarios basados en la cotidianidad, la horizontalidad y el quehacer colectivo. Desde este espacio de resemantización:

... se establecen entonces las diferencias con las generaciones anteriores, y solo allí cobran sentido las distinciones respecto a los procesos político-culturales experimentados por las diversas generaciones: es decir, dictadura-democracia, partidos políticos-generación descreída de la política partidaria, la cultura del consumo, las tecnologías, la globalización, el individualismo, las formas disímiles de organizarse y participar, los temas por los cuales «abanderarse», etc. Todos estos matices reflejan las diferencias que pueden perjudicar la comunicación y el entendimiento entre generaciones y con ello la no comprensión de las diferentes formas de participar, de ejercer la democracia, de ser visibles en la sociedad y de ser sujetos políticos (Aguilera, 2010:96).

A partir de esta visión, pareciera que lo que intenta hacer el movimiento estudiantil es operar una revolución simbólica que implica una «redefinición de los códigos sociales, una impugnación de las relaciones sociales y la creación de símbolos que ponen en duda el propio sistema de representaciones sociales hegemónico» (Portillo et al., 2012:156). Reconocida esta disputa por los significados, uno de sus líderes sugiere que el mayor logro del movimiento iniciado en 2011 ha sido cambiar el sentido común de las personas (Jackson, 2012), cuestión que equivaldría a un cambio de mentalidad, un cambio de para- 
digma sobre la noción de colectividad. De esta manera, las resignificaciones juveniles instalan interrogantes sobre «las reubicaciones de los lugares de enunciación en que se emplazan los distintos actores de un conflicto, expresando de esta manera nuevas relaciones de fuerza, usos diferenciados y diferentes de los discursos sociales, constituyendo en estratégico el control de dichas codificaciones y matrices discursivas» (Portillo et al., 2012:156).

Las posibilidades que tienen los jóvenes de replantear el sentido de su acción política se relacionan estrechamente con el modo en que ellos comunican sus vínculos ciudadanos en la historia reciente. Esto implica que la juventud incorpora los discursos que la sociedad proyecta en y sobre ella, pero no necesariamente con ella. Lo anterior deviene en un rechazo radical al sistema social que aparece como generador de desigualdades y vulneración de derechos, convirtiéndose para ellos en un blanco de ataque. De allí que resulte esencial explorar qué nuevos significados construyen los jóvenes sobre su acción, con el propósito de redefinir los lazos que fundamentan sus prácticas de protesta y disidencia política.

\section{COMUNICACIÓN ONLINE:}

\section{AMPLIAR LOS LÍMITES DE LO DECIBLE}

El lienzo colgado en 1967 en el frontis de la Pontificia Universidad Católica de Chile contenía la leyenda: «Chileno: El Mercurio miente». Esta acción respondía al tratamiento noticioso en que había incurrido el periódico de la derecha empresarial, tergiversando la movilización que los jóvenes llevaban adelante en el proceso de Reforma Universitaria (Araya, 2008). Años más tarde los estudiantes actualizaban este recordatorio: «Chileno: 44 años después El Mercurio aún miente», guiados por un doble propósito comunicativo: por un lado, advertían que la tendencia manipuladora de la prensa hegemónica permanecía inalterable, $y$, por otro, insistían en la toma de consciencia estudiantil respecto de estas prácticas informativas; es decir, daban cuenta de la memoria del movimiento.

Cuatro décadas antes los jóvenes se apropiaban discursivamente del espacio público, como era el caso de paredes y fachadas, para responder a los embates de las elites político-mediáticas. Hoy extienden dicha actuación a los espacios virtuales que han aprendido a gestionar estratégicamente para expresar sus propios mensajes. Los modos en que esta confrontación es mediada y mediatizada no pueden ser sufi- 
cientemente explicados sin recurrir a su naturaleza simbólica, a saber, al papel que desempeñan los medios semióticos utilizados. La acción colectiva del movimiento estudiantil es modelada y estructurada sobre la base de prácticas comunicativas con las cuales irrumpen y perviven en la escena social, apropiándose de espacios simultáneos que operan como lugares de resistencia (Oslender, 2012): las calles, las aulas y las pantallas. No obstante, hasta ahora, la interacción de estos espacios no había signado la actuación del movimiento con tal especificidad.

\section{a) Discurso e historicidad: mover el horizonte de lo posible}

Es ya conocido en el ámbito de los estudios discursivos el planteamiento de que los discursos constituyen prácticas sociales, no obstante, pocas veces se enfatiza en la idea de que los discursos también son hechos históricos (Angenot, 2010). Según este autor, «en todas las épocas reina una hegemonía de lo pensable» (2010:16), porque las ideas que predominan en un momento dado están inscritas en contextos sucesivos, medios e instituciones que las adaptan y hacen algo con ellas, proveyendo una cointeligibilidad desde la cual los acontecimientos se vuelven aprehensibles. Para Angenot, no hay movimientos sociales sin un discurso de acompañamiento que les confiera sentido y los legitime. Desde esta perspectiva, los estudiantes se han propuesto «mover el horizonte de lo posible», en relación con la función social que pueden desempeñar sus discursos para subvertir la hegemonía de lo pensable y construir nuevos espacios de significación.

Arditi (2012) sugiere que el movimiento estudiantil chileno perturba el statu quo de diferentes formas, siendo la más relevante la de cuestionar los «modales políticos» del país. Para este autor, esta impugnación procede de la destrucción traumática de la democracia con el Golpe de Estado, lo que trae como consecuencia una suspensión histórica que impone los límites de lo decible: en la postdictadura, los jóvenes crecen bajo un pacto de silenciamiento que les impide significar la memoria colectiva, interpretar el pasado en relación con el presente y hacerse conscientes de su condición de ciudadanos (Achugar, 2011). Los estudiantes rechazan el sistema sociopolítico heredado del régimen, al tiempo que intentan recuperar un proyecto de sociedad que les fue arrebatado, incluso antes de nacer. La movilización estudiantil propone, pues, una resignificación histórica: tal vez los chilenos ahora puedan recoger su historia desde donde la dejaron en 1973 y empezar su 1974 (Arditi, 2012). 
Al establecerse un vínculo entre discursividad e historicidad se observa cómo los textos circulantes en una sociedad se descomponen, devaluándose con ellos los sistemas de creencias que resguardan (Angenot, 2010). Cuando los estudiantes se proponen una lucha discursiva con las elites dominantes, encarnan a su vez una lucha generacional por los significados que estas han protegido. Los jóvenes, por tanto, se erigen como la vanguardia de un movimiento más amplio que reclama una nueva institucionalidad, y funda nuevos espacios de enunciación para las voces resistentes. Desde esta perspectiva, «los discursos no forman complejos recíprocamente permeables. Los enunciados no deben tratarse como 'cosas', como nómadas, sino como 'eslabones' de cadenas dialógicas» (Angenot, 2010:25), cualidad que los jóvenes han recuperado en sus prácticas comunicativas mediante la apropiación de lugares de enunciación simultáneos, a fin de romper la estrechez monosémica con que han operado los discursos hegemónicos.

Los estudiantes se enfrentan a «una norma pragmática que define en su centro a un enunciador legítimo, quien se arroga el derecho de hablar sobre 'alteridades' determinadas en relación con él» (Angenot, 2010:42), produciendo así formas de discriminación e ilegitimidad con las que se circunscribe su acción. Según Angenot, existen reglas generales de lo pensable y lo decible - una tópica, una gnoseológica- que determinan en conjunto lo aceptable discursivo de una época. En el contexto de las movilizaciones estudiantiles, lo aceptable entra en crisis y se vuelven visibles las disputas por las representaciones, las estrategias discursivas que las modelan y los medios semióticos que las visibilizan en la esfera pública. Debido a que todo acto discursivo es también, necesariamente, un acto de conocimiento (Orlandi, 2012), es posible acceder a la función sociocognitiva de los discursos que soportan maneras en que la realidad puede ser esquematizada, precisando cómo ciertos usos del lenguaje traducen estas luchas por los significados.

En esta línea, Orlandi introduce la noción de memoria discursiva para dar cuenta «del saber discursivo que posibilita todo decir y que retorna bajo la forma de lo preconstruido, lo ya dicho que está en la base de lo decible» (2012:38). Este interdiscurso pone a disposición decires que afectan el modo cómo el sujeto crea significados en situaciones comunicativas dadas. De esta forma, el discurso se compone tanto por su configuración lingüística como por su historicidad, conformándose en la confluencia de dos ejes: el de la memoria (constitución) y el de la actualidad (formulación). Así, al analizarse los discur- 
sos que modelan representaciones sobre la acción política juvenil, es posible construir lecturas que permiten tomar en cuenta los efectos de la experiencia histórica compartida, y explicitar su relación con los textos en virtud de saberes y recuerdos comunes.

Para el análisis de la comunicación online resultan relevantes dos nociones sugeridas por Orlandi (2012): «paráfrasis» y «polisemia». Estas constituyen fuerzas que trabajan continuamente el decir, desvelando una doble tensión significativa entre lo mismo y lo diferente. Los procesos de mediación, mediatización y metarrepresentación (Pardo, 2009) que ajustan los mensajes difundidos a los espacios virtuales, muestran cómo estos se modelan y actualizan sobre la base de textos ya disponibles, de forma material en otros soportes públicos, y de forma simbólica en las memorias intrageneracionales compartidas. Especialmente, la gestión colaborativa que signa la interacción de los estudiantes en redes sociales da cuenta de esta reapropiación en donde persiguen una autorrepresentación positiva.

De acuerdo con Orlandi, «es en ese juego entre paráfrasis y polisemia, entre lo ya dicho y por decir que los sujetos y los sentidos se mueven, hacen sus trayectos, (se) significan» (2012:43). Dicho juego atesta la confrontación entre lo simbólico y lo político, pues todo decir - y lo vuelto a decir - es marcado ideológicamente. Es posible acceder, entonces, a aquellos espacios donde los actores sociales y su capacidad de significación, por la repetición, están siempre tocando tangencialmente lo nuevo, lo posible, en un contexto regido por la simbolización de las relaciones de poder. Así es como los espacios de enunciación que son constitutivos de los discursos juveniles se tocan con las esferas institucionales, proyectando fuerzas en pugna que subvierten sus posiciones en la comunicación.

En este contexto, apunta Angenot (2010), se distingue la ruptura crítica de la norma pragmática, proceso habitual por el que las crisis se instalan. Las movilizaciones operan estos momentos de quiebre y los jóvenes desarrollan prácticas comunicativas estratégicas para desplegarse en ellos. En este sentido, «es poco decir que los textos aparecen 'sobre el fondo de la historia'; su misma significación e influencia son historia» (Angenot, 2010:75). Lo mismo es cierto para sus actividades, en palabras de Arditi (2012), los manifestantes no tienen un plan, ellos son el plan: operan un poder-decir y un poder-hacer en forma simultánea.

Se asume que los discursos tienen la capacidad de subvertir las estructuras sociales, porque alteran los órdenes sociales en virtud de 
nuevos órdenes comunicativos, los que significan por su memoria e historicidad. Siguiendo a Arditi (2012), los movimientos sociales actúan sobre la base de performativos políticos; es decir, transforman la realidad cuando enuncian la necesidad de transformarla: comienzan a experimentar el cambio deseado mientras luchan por él. Los estudiantes se convierten así en lo que Arditi (2012) denomina mediadores evanescentes, son operadores de un poder constituyente y funcionan como portadores del cambio social y una política emancipadora; marcan el comienzo de un orden diferente y luego desaparecen, aunque dejando algo detrás: su historia.

\section{b) Espacios de resistencia estudiantil: las calles, las aulas y las pantallas}

Ampliar los límites de lo decible involucra que lo que puede ser dicho se circunscribe históricamente mediante memorias y saberes. Por tanto, los discursos con los cuales los estudiantes persiguen «mover el horizonte de lo posible» requiere de la construcción de espacios de enunciación funcionales a la disidencia política, de allí que las prácticas comunicativas trasciendan diversos lugares de resistencia para operar las transformaciones simbólicas requeridas por los actores movilizados.

Desde esta perspectiva, el movimiento estudiantil de postdictadura ha ocupado progresiva y paralelamente tres espacios: las calles, las aulas y las pantallas. En dichas ocupaciones, la acción colectiva se ha orientado a la exposición pública del conflicto social, específicamente a la expresión de su protesta para la búsqueda de legitimación ciudadana. Los estudiantes, apoyados en el aprendizaje histórico provisto por sus experiencias de movilización previas, conciben la comunicación de su lucha política como un núcleo de actuación estratégico, destinado a sobrepasar las limitaciones impuestas por la institucionalidad gubernamental y policial que los constriñe.

Marchar por las avenidas neurálgicas de las principales ciudades del país conforma la primera manifestación de insatisfacción con el modelo educativo imperante. '\#Nosvemosenlascalles' se instala no solo como una consigna recurrente para difundir convocatorias masivas por internet, sino que, además, se configura como una práctica constitutiva del movimiento que ha descifrado en las congregaciones multitudinarias una de sus principales claves de visibilización. No obstante, las marchas se convierten en blancos deseados por las elites 
político-mediáticas, lo que conduce a la reformulación de los repertorios de movilización, a fin de imponer otros horizontes de interpretación con los cuales contrarrestar estos intentos estereotipizadores.

Esta apertura ha sido estudiada por diversos investigadores desde la «revolución pingüina» del 2006, quienes han hablado de una culturalización de la política (Valenzuela, 2007) para subrayar cómo los jóvenes optan por formas de comunicación que convierten la resistencia callejera en creación artística. Así, los flashmob viralizados en redes sociales (el thriller o la genkidama por la educación), las intervenciones públicas (la besatón o las 18:00 horas de maratón alrededor del Palacio de La Moneda), y otras iniciativas como cicletadas, pasacalles, dramatizaciones y cuerpos pintados, han desafiado a los medios de comunicación obligándolos a realizar coberturas menos sesgadas. Esta caracterización coincide con aquella ofrecida por Martín Rojo (2013), toda vez que los jóvenes no solo se reapropian creativamente de los espacios urbanos conformando nuevos paisajes lingüísticos móviles, sino que, además, dislocan los lugares preestablecidos de la política, movilizándolos con sus cuerpos en tránsito por la ciudad.

La actuación política no se agota en la performatividad con la que los estudiantes intentan transformar los espacios públicos. Los jóvenes reconocen, en su tradición organizativa, la necesidad de basar su acción colectiva en proyectos programáticos que articulen los objetivos grupales a nivel nacional. Una de las características que posibilita la permanencia del movimiento estudiantil chileno es una estructura orgánica compuesta por las federaciones estudiantiles universitarias: la Confederación de Estudiantes de Chile (CONFECH) y el Movimiento de Estudiantes de Educación Superior Privada (MESUP) y las organizaciones secundarias: Coordinadora Nacional de Estudiantes Secundarios (CONES) y Asamblea Coordinadora de Estudiantes Secundarios (ACES). En este sentido, una vez que las manifestaciones logran captar la atención ciudadana se vuelve prioritaria una comunicación estratégica de las denuncias y demandas del movimiento, práctica que ha sido suficientemente soportada por las redes sociales. Los estudiantes hacen circular petitorios y declaraciones públicas que son el resultado de un arduo trabajo de bases, fruto de asambleas permanentes en las que se evalúan las acciones del movimiento en términos de oportunidades políticas y formas de participación.

Cuando los procesos de negociación con las autoridades políticas se agotan, el movimiento radicaliza su acción tomándose los establecimientos educativos. Los últimos años de movilización registran ocupa- 
ciones de liceos y universidades superiores a los seis meses, a las que se han añadido otras formas de presión como las huelgas de hambre. En las tomas se reconocen rituales de participación bien establecidos, que en la mayoría de los casos convoca a otros actores educativos como personal docente, paradocente y apoderados. Los jóvenes no solo clausuran el ingreso a los establecimientos, sino que se disponen a vivir en ellos generando ricas experiencias de socialización política, muchas de las cuales han sido registradas documentalmente. No obstante la decisión concertada de los estudiantes, las tomas se convierten en escenarios de violenta represión policial, lo que lleva a constantes desalojos y retomas de parte de los estudiantes.

Redes sociales como Facebook y Twitter conforman espacios donde convergen aquellos significados construidos en las calles y las aulas. Desde el 2011 a la actualidad los usos online han crecido exponencialmente, estableciéndose como canales informativos privilegiados para la articulación del movimiento. Páginas como Estudiantes Informados se han convertido en medios influyentes seguidos por cientos de miles de adherentes. Estos ofrecen la actualidad noticiosa a toda persona que desee saber del movimiento por vías alternativas a las provistas por los medios de comunicación tradicionales. Estas páginas tienen la particularidad de ser creadas y administradas desde las bases estudiantiles, sin intervención partidista y con una marcada tendencia a la construcción colaborativa de contenidos que abarcan las distintas experiencias de movilización local y regional.

Este tipo de comunicación constituye uno de los rasgos distintivos del movimiento estudiantil, ya que posibilita la interacción directa, al tiempo que soporta la negociación de significados políticos. Aunque, a simple vista, pareciera que los estudiantes solo se disponen a reponer noticias ya difundidas por la prensa oficial, lo que subyace a esta opción es la selección estratégica de contenidos relevantes para la autorrepresentación positiva del movimiento. Dicha relevancia (Yus, 2010) se expresa en la necesidad de poner foco sobre ciertos temas que configuran la base de conocimientos compartidos a partir de los cuales se comprende la acción juvenil, modelándose la identidad colectiva mediante la construcción de entornos cognitivos compartidos (Sperber y Wilson, 1994) derivados de la gestión noticiosa online.

De este modo, la selección de unos contenidos noticiosos por sobre otros activa dinámicas de discusión, que no dependen ni están supeditados a las esferas adultas y poderosas. Las redes sociales devienen así en espacios de resistencia que se expanden como lugares de 
diálogo y resignificación. Las pantallas funcionan, entonces, como emplazamientos del discurso político juvenil.

Así como los estudiantes cambian el signo cultural de las calles y las aulas para asignarles —o retribuirles - un carácter político como lugares de discrepancia y reflexibilidad, las redes sociales dejan de ser espacios de ocio para convertirse en enclaves de socialización que resemantizan las experiencias de movilización. A la jerarquización, la verticalidad y la temporalidad impuestas por la política formal, los jóvenes confrontan prácticas de participación simétricas, horizontales e instantáneas, donde el poder no reside en las estructuras o las etiquetas sociales, diluidas ya en la red (Yus, 2010), sino en el valor de los saberes que subyacen a la comprensión e interpretación de los mensajes que, resemiotizados, renuevan el sentido de lo político y persiguen nuevos vínculos entre la ciudadanía juvenil y un particular proyecto de sociedad que reúne sus experiencias y aspiraciones generacionales.

Finalmente, junto con la reposición noticiosa, las funciones informativas online que delinean los estudiantes movilizados abarcan prácticas de construcción de contenidos propios, los que son difundidos con un sentido especialmente contraeducativo. En primer lugar, sustentados en el uso de software y otros recursos de la web 2.0, construyen mensajes con finalidades persuasivas y formativas, muchos de los cuales tienen un carácter irónico y ostentan una gran capacidad de viralización. Por un lado, circulan diseños multimodales que combinan texto e imagen, pudiendo ser ilustraciones o memes digitalizados. Estas construcciones son, al mismo tiempo, objetos de denuncia y de burla, usualmente motivados por situaciones contingentes como procesos de negociación política o situaciones de represión policial. Por otro lado, ha logrado un papel preponderante la elaboración de infografías, videos y convocatorias que explican, por ejemplo, las prácticas con que los dueños de instituciones educacionales incurren en lucro y defraudación, propiciando el sobreendeudamiento y la segregación socioeconómica. Estos mensajes no solo colaboran a la construcción de visiones y objetivos comunes a la movilización, sino que, además, acercan la protesta a la ciudadanía, presentándola como una lucha necesaria y justa.

En segundo lugar, los discursos que circulan por la red son fundamentalmente heteroglósicos y polifónicos; es decir, son parte de una enunciación múltiple que recoge diversas voces y posicionamientos, susceptibles de réplica y contestación. Las interacciones comunicativas incluyen instancias donde la identidad individual se diluye dentro 
del grupo, o bien, momentos en que la inscripción individual es metonímica; es decir, remite a una parte del cuerpo grupal, como los brazos o los puños. Los estudiantes han insistido en definirse como un único 'cuerpo en movimiento', tanto físico como territorial, enfatizando con ello la cohesión nacional que han mantenido en los años consecutivos de lucha. Esta metáfora ha sido trabajada principalmente por medios visuales, como es el caso de los afiches con que se congrega a marchas y paralizaciones. Muchos de ellos actualizan una estética que recupera diseños característicos de las brigadas muralistas de las décadas de los 70 y 80.

En tercer lugar, los cambios en la materialidad de los mensajes y sus soportes implican la conversión de unos modos semióticos en otros, cuestión que a su vez involucra nuevas formas de descodificación e interpretación. Se suceden así cadenas de reproducciones que hacen circular, de un espacio a otro, cánticos callejeros que son convertidos en lienzos o grafitis, que luego son fotografiados y difundidos por la web, erigiéndose en símbolos compartidos por los estudiantes de diversas regiones, superando las fronteras geográficas. Estos procesos de traslado o transposición simbólica aseguran la ocupación y la resignificación de los espacios — reales y virtuales-, en que los jóvenes actúan simultáneamente.

De esta manera, se observa no solo cómo se conforman distintos lugares de discursividad juvenil, sino cómo estos interactúan entre sí, fortaleciéndose mediante la movilización de significados de unos a otros. Dichos movimientos, junto con otorgar especificidad a estos espacios de enunciación política, colaboran en la conformación de marcos interpretativos comunes que sustentan cognitiva e ideológicamente la acción colectiva estudiantil.

\section{CONSIDERACIONES FINALES}

Si bien tiende a pensarse que los logros de los movimientos sociales dependen del grado de efectividad con el que impactan en el contexto sociopolítico cuestionado, se ha discutido ya el carácter performativo que soporta transformaciones a nivel semiodiscursivo y sociocognitivo más allá de las consecuencias factuales. De allí que resulten relevantes diversos lugares de actuación juvenil que funcionan como espacios de negociación de significados y co-construcción de identidades políticas, actualmente conferidos por las redes sociales. Las calles y las aulas son emplazamientos históricamente constitutivos del que- 
hacer estudiantil, no obstante, la irrupción de las pantallas como nuevo lugar de enunciación expande la resistencia juvenil a contraesferas de participación más amplias, móviles e inmediatas, capaces de generar síntesis e hibridaciones simbólicas que profundizan los esquemas compartidos afines a la movilización.

Una perspectiva comunicativa basada en el eje resemiotización/resemantización ayuda a reformular los modos de comprender las prácticas de hetero y autorrepresentación juvenil, pues permite echar luz sobre aspectos divergentes y mutables que impiden lecturas homogéneas y unívocas. Aun cuando se confrontan flujos informativos hegemónicos y contrahegemónicos, el resultado de las disputas por la significación de lo político deja entrever procesos de identificación complejos y en permanente tensión y reconfiguración. Se trata de espacios de discursividad signados por una enunciación múltiple, que si bien favorece la confluencia de sentidos identitarios - como aquellos orientados a los propósitos del movimiento-, también evidencia con mayor nitidez las reacciones de los diversos actores juveniles a hacerse parte de una representación total.

Los significados se negocian sobre la base de argumentos que esclarecen la existencia de: a) conocimientos compartidos, sobre el decurso de las protestas y los procesos políticos entre líderes y autoridades de gobierno; b) actitudes grupales, en torno a sucesos que activan la formulación de ideologías, más moderadas o radicales, como aquellos vinculados con la represión policial; y c) memorias intrageneracionales, respecto de las experiencias de movilización previas («revolución pingüina») o derivadas de vivencias traumáticas no experimentadas (dictadura militar), que actualizan aprendizajes aplicados al devenir de la acción estudiantil.

Los discursos online sobre la acción política juvenil permiten acceder a una base sociocognitiva que recontextualiza las prácticas visibles: los sentidos que los estudiantes movilizan de unos espacios de actuación a otros reconstruyen representaciones sustentadas en una intertextualidad marcada históricamente (Halliday, 1992). Debido que los sentidos interactúan dentro de una jerarquía discursiva que es parte de una matriz sociosemiótica mayor, los modos en que las representaciones pueden modelar marcos interpretativos comunes dependen de una posición particular que pone al alcance unos interdiscursos en lugar de otros — por ejemplo, en relación con la proximidad generacional- De allí que explorar cómo interactúan diversos espacios de discursividad provea nuevas luces para observar el vínculo entre topo- 
logías y gnoseologías emergentes, que articulan los decires juveniles a nuevos y sucesivos contextos de significación.

BARCELONA (ESPAÑA), DICIEMBRE 2014

RECIBIDO: DICIEMBRE 2013

ACEPTADO: JUNIO 2014

\section{REFERENCIAS BIBLIOGRÁFICAS}

ACHUGAR, MARIANA (2011): «Aproximaciones discursivas a la transmisión del pasado reciente: síntesis cualitativa». En T. OTEízA y D. PINTO (editores): En (re)construcción: discurso, identidad y nación en los manuales escolares de historia y de ciencias sociales. Santiago: Cuarto Propio. AGUILERA, OSCAR (2012): «Repertorios y ciclos de movilización juvenil en Chile (2000-2012)». Revista Utopía y Praxis Latinoamericana, Vol. 17, №57. Maracaibo: Universidad del Zulia.

— (2010): «Cultura política y política de las culturas juveniles». Revista Utopía y Praxis Latinoamericana, Vol. 15, №50. Maracaibo: Universidad del Zulia.

(2009): «Los estudios sobre juventud en Chile: coordenadas para un estado del arte». Última Década №31. Valparaíso: CIDPA.

Agurto, IRENe; MANUEl CANALES y GONZALO DE LA MAZA (1985): Juventud chilena. Razones y subversiones. Santiago: ECO/FOLICO/SEPADE.

ANGenOT, MARC (2010): El discurso social. Los límites históricos de lo pensable y lo decible. Buenos Aires: Siglo XXI.

ARAYA, PedRo (2008): «El Mercurio miente (1967): siete notas sobre escrituras expuestas». Revista Austral de Ciencias Sociales N$^{\circ} 14$. Valdivia: Universidad Austral de Chile.

ARDITI, BENJAMín (2012): «Insurgencies Don't Have a Plan - They are the Plan: Political Performatives and Vanishing Mediators in 2011». JOMEC Journal $\mathrm{N}^{\circ} 1$. Cardiff: Cardiff University.

BENNETT, W. LANCE (2003): «Civic Learning in Changing Democracies».

CABALIN, CRISTIAN (2012): «Neoliberal Education and Student Movements in Chile: Inequalities and Malaise». Policy Futures in Education $\mathrm{N}^{\circ} 10$. Oxford: Symposium Journals.

CÁRDENAS, CAMILA (en prensa): «Jóvenes e (in)visibilización histórica: modos de representación ideológica de la juventud chilena en el pasado reciente (1970-1990)». Revista Signos. Estudios de Lingüística. Viña del Mar: Pontifica Universidad Católica de Valparaíso. 
(2013): «La representatividad en disputa: estrategias conversacionales de dos líderes juveniles en una interacción política televisada». Revista Discurso \& Sociedad, Vol. 7, №3.

(2012): «¿Dónde debe emplazar su ojo la historia? (In)visibilización de las y los jóvenes en discursos disciplinares que recuperan el pasado reciente chileno (1970-1990)». Revista Discurso \& Sociedad, Vol. 6, №2. (2011a): «Análisis de tres modos de representación ideológica construidos en discursos especializados sobre juventud chilena producidos entre 1970 y 1990». Revista de la Asociación Latinoamericana de Estudios del Discurso, Vol. 11, No2. Bogotá: ALED.

(2011b): «(In)visibilización juvenil: acerca de las posibilidades de las y los jóvenes en la historia reciente del país». Última Década º35. Valparaíso: Ediciones CIDPA.

Chaves, MARIANA y Pedro NúÑEZ (2012): «Youth and Politics in Democratic Argentina: Inventing Traditions, Creating New Trends (19832008)». Young, Vol. 20, Nº4. London: SAGE.

- (2005): «Juventud negada y negativizada: representaciones y formaciones discursivas vigentes en la Argentina contemporánea». Última Década $\mathrm{N}^{\circ} 23$. Valparaíso: Ediciones CIDPA.

ChÁvez, ANNy y LoRENA POBLETE (2006): «Acción colectiva y prácticas políticas juveniles». Última Década №25. Valparaíso: Ediciones CIDPA.

DUARTE, ClAUdIO (2012): «Sociedades adultocéntricas: sobre sus orígenes y reproducción». Última Década N³6. Valparaíso: Ediciones CIDPA.

FEIXA, CARLES; INÊS PEREIRA y JEFFREY JURIS (2009): «Global Citizenship and the 'New, New' Social Movements: Iberian Connections». Young, Vol. 17, No4. London: SAGE.

FERNÁNDEZ, CHRISTIAN (2012): «Ciudadanía juvenil y nuevas formas de participación a través de la conectividad». Culturales, Vol. 8, No15. Mexicali: Universidad Autónoma de Baja California.

GARCÉS, MARIO (2012): El despertar de la sociedad. Los movimientos sociales en América Latina y Chile. Santiago: LOM.

JACKSON, GIORGIO (2012): El país que soñamos. Debate: Santiago.

GOICOVIC, IGOR (2000): «Del contrato social a la política social. La conflictiva relación entre los jóvenes populares y el Estado en la historia de Chile». Última Década Nº12. Valparaíso: Ediciones CIDPA.

GuZMÁn CONCHA, CÉSAR (2012): «The Students’ Rebellion in Chile: Occupy Protest or Classic Social Movement?». Social Movement Studies, Vol. 11, No3-4. London: Routledge.

HALlidAY, MichAel (1992): «The History of a Sentence». In V. FoRTUNATI (Ed.): La cultura italiana e le letterature straniere moderne. Bologna: Longo Editore.

HARris, ANITA; JoHANNA WYN y SALEM YounEs (2010): «Beyond Apathetic or Activist Youth: 'Ordinary' Young People and Contemporary». Young, Vol. 18, Nº1. London: SAGE. 
HERKMAN, JuHA (2012): «Convergence or Intermediality? Finnish Political Communication in the New Media Age». Convergence, Vol. 18, No 4 . London: SAGE.

JELIN, EliZABETH y DiEGO SEMPOL (2006): El pasado en el futuro: los movimientos juveniles. Buenos Aires: Siglo XXI.

LECHNER, NORBERT (2006): Las sombras del mañana. La dimensión subjetiva de la politica. Santiago: LOM.

MARGULIS, MARIO y MARCELO URRESTI (1996): La juventud es más que una palabra. Ensayos sobre cultura y juventud. Buenos Aires: Biblos.

MARTín RoJO, LuISA (2013): «Paisajes lingüísticos de indignación. Prácticas comunicativas para tomar las plazas». Anuari del Conflicte Social 2012. Barcelona.

y RACHEL WhITTAKER (1998): Poder-decir: o el poder de los discursos. Madrid: Arrecife.

MillaleO, SALVADOR (2011): «La ciberpolítica de los movimientos sociales en Chile: algunas reflexiones y experiencias». Revista Anales, Vol. 7, $\mathrm{N}^{\circ}$ 2. Santiago: Universidad de Chile.

MUÑOZ, VíctoR (2011): «Juventud y política en Chile: hacia un enfoque generacional». Última Década №35. Valparaíso: Ediciones CIDPA.

— (2004): «Imágenes y estudios cuantitativos en la construcción social de 'la juventud chilena'. Un acercamiento histórico (2003-1967)». Última Década $\mathrm{N}^{\circ} 20$. Valparaíso: Ediciones CIDPA.

ORlandi, ENI (2012): Análisis de discurso. Principios y procedimientos. Santiago: LOM/UMCE.

OSLENDER, ULRICH (2012): «Espacializando la resistencia: perspectivas de espacio y lugar en las investigaciones de movimientos sociales». En E. RESTREPO y M. V. URIBE (comps.): Antropologías transeúntes. Bogotá: Instituto Colombiano de Antropología e Historia.

ÖSTMAN, JOHAN (2012): «Information, Expression, Participation: How Involvement in User-Generated Content Relates to Democratic Engagement among Young People». New Media \& Society, Vol. 14, №6. London: SAGE.

OTEízA, TERESA (2006): El discurso pedagógico de la historia. Un análisis lingüístico sobre la construcción ideológica de la historia de Chile. Santiago: Frasis.

PARDO, NEYLA (2009): «Los bordes en la significación discursiva y la mediación mediatizada». Revista Comunicación y Ciudadanía $\mathrm{N}^{\circ} 1$. Bogotá: Universidad Externado de Colombia.

PORTILLO, MARICELA et al. (2012): «De la generación X a la generación @. Trazos transicionales de identidades juveniles en América Latina». Última Década $\mathrm{N}^{\circ} 37$. Valparaíso: Ediciones CIDPA.

RicoeUr, PAUl (2010): La memoria, la historia, el olvido. Buenos Aires: Fondo de Cultura Económica. 
ROVIRA SANCHO, GUIOMAR (2013): «Activismo mediático y criminalización de la protesta: medios y movimientos sociales en México». Convergencia, Vol. 20, Nº61. Toluca: Universidad Autónoma del Estado de México.

SAlAZAR, GABRIEL y Julio PINTO (1999): Historia contemporánea de Chile. Niñez y juventud. Vol. V. Santiago: LOM.

SPERBER, DAN y DEIRDRE WILSON (1994): La relevancia. Madrid: Visor.

TARROW, SIDNEY (2011): El poder en movimiento. Los movimientos sociales, la acción colectiva y la política. Madrid: Alianza Editorial.

THEOCHARIS, YANNIS (2012): «Cuts, Tweets, Solidarity and Mobilization: How the Internet Shaped the Student Occupations». Parliamentary Affairs $\mathrm{N}^{\circ} 65$. Oxford: Oxford University Press.

TILly, Charles y LeSley WoOD (2010): Los movimientos sociales, 1768 2008. Desde sus orígenes a Facebook. Crítica: Barcelona.

Trouillot, Michel-Rolph (1995): Silencing the Past: Power and the Production of History. Boston: Beacon Press.

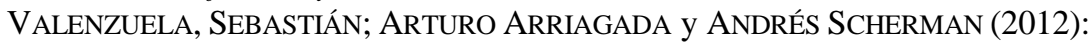
«The Social Media Basis of Youth Protest Behavior: The Case of Chile. Journal of Communication, Vol. 62, №2. Washington: Wiley-Blackwell.

VALENZUELA, KATIA (2007): «Colectivos juveniles: ¿inmadurez política o afirmación de otras políticas posibles?». Última Década N²6. Valparaíso: Ediciones CIDPA.

VROMEN, ARIADne y PhILIPPA COLlin (2010): «Everyday Youth Participation? Contrasting Views from Australian Policy Makers and Young People». Young, Vol. 18, Nº1. London: SAGE.

WARD, JANELle y Claes DE VREESE (2011): «Political Consumerism, Young Citizens and the Internet». Media, Culture \& Society, Vol. 33, №3. London: SAGE.

YUS, FRANCISCO (2010): Ciberpragmática 2.0. Nuevos usos del lenguaje en internet. Barcelona: Ariel. 